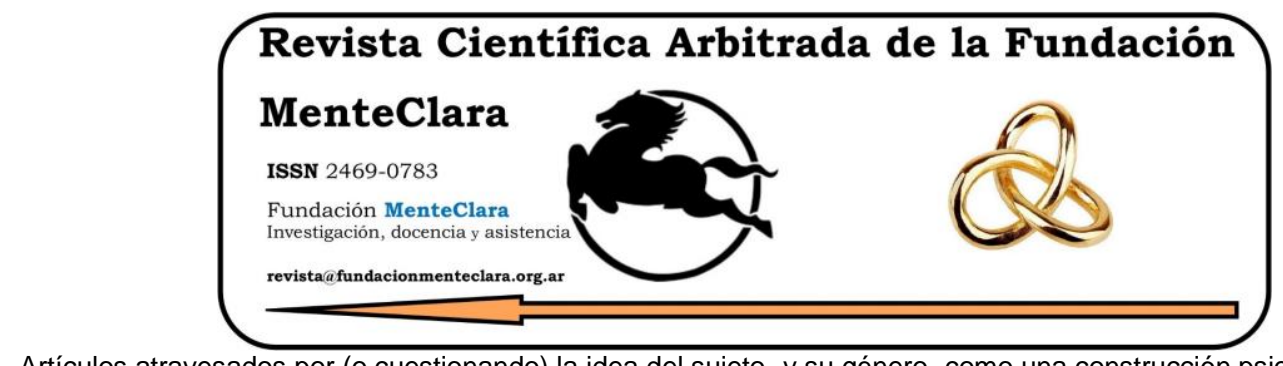

Artículos atravesados por (o cuestionando) la idea del sujeto -y su género- como una construcción psicobiológica de la cultura. Articles driven by (or questioning) the idea of the subject -and their gender- as a cultural psychobiological construction.

Vol. 6 (2021), enero-diciembre

ISSN 2469-0783

https://datahub.io/dataset/2021-6-e222

\title{
DIMENSIÓN SOCIAL DEL DOLOR Y LAS VACUNAS VIP EN EL PERÚ
}

\section{SOCIAL DIMENSION OF PAIN AND VIP VACCINES IN PERU}

Ricardo Arango Olarte ${ }^{1}$, Aparicio Chanca Flores ${ }^{2}$, Jesús Guillermo Caso Álvarez ${ }^{3}$, Antonio Nahuincopa Arango ${ }^{4}$

Cómo citar este artículo / Citation: Arango Olarte R., Chanca Flores A., Caso Álvarez J. G. \& Ñahuincopa Arango A. (2021). Dimensión social del dolor y las vacunas VIP en el Perú. Revista Científica Arbitrada de la Fundación MenteClara, Vol. 6 (222). DOI: https://doi.org/10.32351/rca.v6.222

Copyright: (C) 2021 RCAFMC. Este artículo de acceso abierto es distribuido bajo los términos de la licencia Creative Commons Attribution 4.0 International License (CC BY 4.0). Recibido: 23/04/2021. Aceptado: 29/04/2021 Publicación online: 30/04/2021

Conflicto de intereses: Ninguno que declarar.

\section{Resumen}

El presente trabajo de investigación comienza con el análisis sobre la cuestión acuciante del dolor y sufrimiento generado por la COVID-19, desde la perspectiva social. Luego se centra de modo especial, desde una visión tripartita: ético, antropológico y filosófico de la adquisición y administración de las vacunas por el gobierno peruano, conocido como el caso 'Vacunagate'. En el fondo del asunto se destacan también actitudes egoístas y corruptas que han devenido de la compra de las mascarillas, los medicamentos y el oxígeno.

\footnotetext{
${ }^{1}$ Universidad Nacional del Centro del Perú, Facultad de Antropología, Perú. ricardoarango9@gmail.com

2 Universidad Nacional del Centro del Perú, Facultad de Antropologia, Perú. achanca@uncp.edu.pe

${ }^{3}$ Universidad Nacional del Centro del Perú, Perú. killincha1701@gmail.com

${ }^{4}$ Universidad de Navarra, España. aarango@uncp.edu.pe
} 


\begin{abstract}
This research work begins with the analysis of the pressing issue of pain and suffering generated by COVID-19, from a social perspective. Then he focuses in a special way, from a tripartite view: ethical, anthropological and philosophical, on the acquisition and administration of vaccines by the Peruvian government, known as the 'Vacunagate' case. At the heart of the matter are also selfish and corrupt attitudes that have resulted from the purchase of masks, medicines and oxygen.
\end{abstract}

Palabras Claves: dolor; pandemia; Covid-19; ética; corrupción política

Keywords: pain; pandemic; Covid-19; ethics; political corruption 


\section{Introducción}

En el presente artículo intentamos dilucidar cómo nos afecta el dolor y el sufrimiento como sociedad a escala local, nacional e internacional, puesto que el hombre es social por naturaleza. Realmente, es significativo considerar el dolor en su dimensión social: el coronavirus no acaba con el mundo, pero sí con la vida de los seres humanos. Pues, la pandemia nos afecta en cuanto animales de la especie humana como seres finitos, frágiles y vulnerables.

Para ahondar el tema, se analiza desde la perspectiva antropológica, filosófica y ética la adquisición y la administración de las vacunas "VIP" en el Perú, que constituyó un escándalo internacional. El problema troncal de estos actos poco éticos se resume en la corrupción, que es la real 'pandemia' de todos los tiempos y que hasta el momento no tiene remedio. Además, esta lacra social tiene que ver con el egoísmo que cada uno de nosotros lleva en su interior, nuestro leviatan en terminología de Tomás Hobbes.

\section{La perspectiva social del sufrimiento humano}

El coronavirus ha marcado nuestras vidas con hechos trascendentales y devastadores que nos mantiene sumidos en el dolor y sufrimiento a la humanidad. Además, vislumbró la fragilidad y la vulnerabilidad de la vida en el ámbito personal, social e institucional. Por otra parte, los daños colaterales ocasionados como el incremento de familias enteras que han sido empujados a la pobreza, como el hambre generalizado y los problemas de salud mental agravado que trajo como consecuencia una severa exclusión de los más vulnerables (Noreña, 2020: 2).

La crisis sanitaria de la COVID-19 ha ocasionado una crisis politica e ideológica. Debido a la incapacidad del Estado neoliberal imperante, que 
está cegado a la realidad, no se dio la verdadera importancia a la salud pública. A pesar de todo, el personal médico aún sigue laborando día a día en condiciones deplorables. En desafortunadas ocasiones se han contagiado con el coronavirus, muchos de ellos han fallecido, lo cual constituye un verdadero problema nunca irresoluble y una gran preocupación y sufrimiento familiar.

Por lo mismo, como alternativa de seres pensantes, en esta situación coyuntural debemos aprender a ser empáticos, solidarios y altruistas con la nueva forma de convivencia (Di Franco, 2020: 2-3). Entre tanta muerte y dolor seamos más sensibles y humanos para buscar la esencia de la justicia humana (Giroux \& Proas, 2020: 1).

Ante el eminente rebrote de la segunda ola, ninguna de las politicas sanitarias emitidas por el Gobierno ha sido eficiente, habria que preguntarse, ¿cuáles fueron las causas de esta ineficiencia? Podemos enunciar algunas de ellas como detalles importantes: organización y asistencia a diversas fiestas denominadas "COVID", la celebración de la fiesta de navidad y año nuevo, las celebraciones de cumpleaños, matrimonios, aniversarios y fiestas patronales sin respetar los protocolos de salubridad; las visitas familiares y muchos otros. Como muestra de esta irresponsabilidad podemos citar el caso del día 16 de diciembre de 2020 en la provincia de Sullana, región Piura. Han hecho largas colas para adquirir cajas de cerveza como fuera un alimento básico de supervivencia. Por supuesto, las consecuencias funestas no tardaron: los meses de enero, febrero y marzo de 2021, aumentaron exponencialmente los casos de contagio, provocando colapso en los hospitales y ocasionando la demanda del oxígeno para salvar vidas humanas. Así, a diario muchas familias estuvieron buscando oxígeno y haciendo largas colas para adquirirlo. El oxígeno se convirtió en un preciado elemento y de suma utilidad en momentos en que la vida era arrebatada de forma 
intempestiva. Cada día se experimentaba evidentemente el dolor y sufrimiento social en grandes dimensiones a nivel nacional, regional y local.

En estas circunstancias coyunturales, el Gobierno del expresidente Vizcarra, creó la Comisión Multisectorial para la adquisición de las vacunas e inmunizar a casi 25 millones de peruanos. Se avizoraba un denudado esfuerzo y sin precedentes, era un plan ambicioso, un anuncio presidencial alentador para todos. ¡Íbamos a contar por fin con las preciadas vacunas! Pero, el tiempo demostró lo contrario, solo eran mentiras adornadas con marcado paternalismo y pseudopreocupación por la población. La prensa empalagosa presentaba diariamente solo falacias. La alta cúpula gobernante, faltó a la verdad y nunca fue honesta.

En estos tiempos de crisis, la población necesita saber la verdad no importa que sea dolorosa, ya no más mecidas ni engaños. Vizcarra mintió con descaro y de forma sistemática al país (Campos, 2021). Hasta ahora, muchas personas siguen preguntándose cómo pudo suceder eso y no salen del asombro e indignación por la incuestionable traición del exmandatario. "Nada más honesto y sincero que el egoísmo y los actos encubiertos" (Gastelumendi, 2021). Estas acciones temerarias y ventajosas han desnudado, una vez más, a la élite gobernante que aprovecharon el cargo para sacar ventaja. Se aseguraron con una vacuna, que para el país era tan escasa pero deseada por miles de desesperados.

“...inocentemente, pensabas que lo peor ya estaba pasando y que esto nos haria mejores personas. Que difícil de comprender. Olvidamos que en este mundo existen personas farsantes que nos pedia paciencia cada mediodía (Martín Vizcarra), la falsa capitana de barco (Pilar Mazzetti), la cinica que no podia darse el lujo de enfermarse (Elizabeth Astete), el canalla que cambió vacunas por una porción de wantán 
(German Málaga), la lobista que en silencio se saltaba la cola (Cecilia Blume)" (Ortiz, 2021).

Por otra parte, el país se polarizaba por las disputas entre el poder ejecutivo y legislativo. En este trajin asume la presidencia de la República, Francisco Sagasti, en pleno caos social que azota al país y que está al borde del precipicio de la inestabilidad politica, social y económica. El nuevo mandatario debería llevar adelante las negociaciones de la compra de las vacunas. Es una agonía sin fin que cada día nos hace más vulnerables. Todos estamos en la misma odisea que se torna muy complicado, porque la realidad es tan cruda, clamando que de algún lado venga un mensaje de esperanza. "Sálvese quien pueda, mejor solo que mal acompañado" es un refrán que describe toda la situación que nos ha tocado vivir, una vez más nos equivocamos y estamos tan mal en el país (Campos, 2021).

Para el antropólogo Cesar Nureña el tema de la argolla viene desde varias décadas, para la coyuntura actual calza el término "argolla" donde un grupo de políticos que están inmersos en el caso vacunagate se define: “el privilegio, la gollería, la vara". Y los involucrados defendian lo indefendible de que "No se trata de privilegios, se trata de que las cosas funcionan asî". Cómo es posible que un acto irregular tenga una respuesta de cinismo. Con todas las letras podemos señalar que merecen una sanción, por el aprovechamiento indebido sin compadecerse del dolor ajeno, solo buscando su propio beneficio (Mendoza, 2021): “...nos haria un gran favor para levantar el espiritu nacional si nos contara de alguien que se negó a recibir su dosis salvadora, alguien que le dijo no doctor, mejor vacunemos antes a la primera linea" (Álvarez, 2021).

Estos acontecimientos inmorales y corruptos no hacen otra cosa sino dañar al Perú en sus diversas facetas: social, económica y política, haciéndonos un país tan desigual (Del Río, 2021). Ante esta desigualdad 
ocasionada por la corrupción, emergieron personas sin corazón que aprovechando la crisis se hacen más ricos causando más desconcierto en las personas menos favorecidas que se vuelven más pobres y están inmersos en el dolor y sufrimiento.

Cabe resaltar, desde esta perspectiva, que el sufrimiento ha estado en medio de cada persona, familia e Institución, sobre todo, en nuestros corazones. Fenomenológicamente, ha sacado a relucir todos nuestros sentimientos de sufrimiento como nunca imaginamos pasar, porque la tristeza y la melancolia matan lentamente, testimonios desgarradores como estas.

"Hace una semana murió mi prima. Una hermana para mi, una hija para mi madre. Parecía que habiamos logrado arrebatársela a la muerte, pero un día nos faltó el oxígeno y pese a nuestra búsqueda frenética, cuando lo hallamos, fue tarde. Se fue agitada, desesperada por aire, una muerte injusta que no merecía su noble corazón. Eso es lo que me desconsuela y genera una rabia profunda. Buscando que a través de la pena de mi familia se tome conciencia porque el dolor es indescriptible. En esa búsqueda hallé a otros que como yo sufren una pérdida irreparable e injusta" (Montero, 2021).

\section{Oportunismo e inhumanidad en las vacunas VIP}

La élite de la política peruana, cambió de denominación a las vacunas de investigación a: vacunas de cortesía o de donación para disimular el acto voluntario y plena conciencia con que actuaron.

Realmente toda esa conveniencia es producto de la presteza y sagacidad con que actúan con frecuencia las autoridades de turno de nuestra patria. En este caso particular de las vacunas, hace entrever que ya existía un aparato organizado para operar de esta manera y que con 
tanta anterioridad estaba constituida y planificada. Muy dificil de digerir con propiedad tanto fenómeno. Al final de cuentas, si existió una patraña, ya no nos incumbe, todo está consumado. Si fue una ingenuidad y una acción infeliz, nadie cree ni tampoco importa ya. Solo queda tomar la sagrada resignación y acaudalar una nueva enseñanza más.

Los gobernantes de turno se aprovecharon de un ensayo clínico de vacunas, para inocularse personalmente y extendiendo a sus allegados y familiares. Éticamente, pensar primero en uno mismo sin importar el otro es el egoísmo más recalcitrante en una sociedad que debería ser equitativa (Jesús, Sarmento \& Duarte, 2018).

Estos hechos no fueron causas de la renuncia del exmandatario ni de su ministra Mazzetti, sino, consumada la vacuna, sálvese quien pueda. Ya lograron salvarse y a "disfrutar" de la sanidad. Este escándalo ha cavado un profundo forado irremediable en el Perú, como fresa al pastel de la gran corrupción al cual estamos sumidos.

Congresistas, ministros, embajadores y familiares cercanos a este grupo fueron la saga de inescrupulosos que formaron parte de la negligencia atrevida del expresidente que se suscitaron todavía en octubre de 2020. Esa época era el pico de la plena muerte, dolor y consternación y, vuelve a vacunarse en enero de este año, consolidando su desvergüenza, antes de la inmunización oficial y general que empezó.

Todo esto un acto Maquiavélico donde el fin es lo que vale con tal de alcanzar el favor, sin importar las consecuencias (D' Souza, 2020). Esos son los típicos oportunistas que no dejan pasar ni un átomo de ocasión para captar todo lo que ingresa al país y apoderarse cuanto haya para disfrutar a manos llenas, indebidamente.

Claro los peruanos como siempre usamos el perdón, la disculpa, tenemos un cliché de justificar con una frase desgastada "errar es 
humano" y sin saber se arma un castillo de mentirosos, deshonrosos e ignominiosos (Tala \& Valenzuela, 2020). Nadie piensa que eso es de los más ingenuos y a la vez, de los más vivaces, de aquellas personas sin una pizca de consideración y respeto.

En nuestro contexto la frase -Pido perdón- es hipnotizante y su efecto es un saludo a la bandera, una bofetada a la ética, es un insulto a la cordialidad de todos cuanto confiamos en nuestros gobernantes. Muchos han pedido el rodamiento de cabezas o la separación o cese de sus cargos para ser denunciados penalmente, pero eso en nada remedia la situación. A la vez, conociendo el modus operandi de la justicia peruana, los implicados son santas palomitas.

Pasó la primera ola y llegó con mayor fuerza el embate de la segunda ola y quién sabe si viene la tercera ola, la población sigue esperando, pero en medio de este sufrimiento se deja entrever que los más poderosos económicamente ya habrian sido vacunados con su propio peculio, pues esto es una guerra de los más fuertes y se engancha en la Ley del más fuerte. La larga espera de los más débiles

El más endeble, el afectado y el de poca oportunidad constituye el pueblo, la gente de a pie, los que viven de día a día y que no tienen ningún recurso para darse el lujo de comprarse algunas dosis de vacuna para inmunizarse.

La decepción cunde en las zonas marginales, donde la gente sortea el virus en las calles en su afán de vender su producto y comprar el pan para llevar a su humilde hogar.

Es entendible que la actitud de la clase política trae consigo la desconcertación y enojo común y siembra la desconfianza en el pueblo.

Desde tiempos inmemoriales, el peruano vivió guarnecido de valores e inculcado en ética, su filosofia práctica de ama llulla -nunca mentiroso-, 
ama suwa -nunca ladrón- y ama qella -nunca vago- dan cuenta de que su actitud y conducta era de lo más correcto (De Arruda, Marqués \& Álvaro Estramiana, 2020). Ese ejemplo aún pervive hasta hoy, hay aún la lealtad y fidelidad en todas las esferas de la humilde población.

Pero en la esfera del gobierno, de las instituciones e incluso en las universidades estatales, la ética se ha divorciado de la política y de la investigación respectivamente, para fomentar y justificar la corrupción, aunque sea en menor escala.

Hasta ahora se sigue esperando con tanta paciencia empero su desesperación, con la esperanza de que llegue a todos en igualdad de condiciones.

Pero, el dicho de que, el Perú es más grande que sus problemas, deberá hacerse realidad, nuestra expectación larga y tendida debe confluir en la sanidad de todos, en el bienestar general y la recuperación económica del país.

\section{Desde la perspectiva antropológica}

La antropología, como ciencia que estudia al ser humano de forma integral, es decir, considera su dimensión biológica, psicológica y trascendental como también sus manifestaciones sociales y culturales.

Así en su dimensión fisiológica estudia las diferencias raciales, los rasgos somáticos y el proceso de desarrollo del organismo humano, mientras que en el aspecto cultural se trata sobre los procedimientos ideados por el hombre para enfrentarse a su medio natural y su ambiente social; como se aprende, conserva y transmite un cuerpo de costumbres (Herskovits, 1952: 15). Y la dimensión trascendental aborda fundamentalmente la naturaleza, dignidad, el alcance y el sentido de su existencia. 
Los aspectos físicos y culturales influyen en las actitudes, expectativas y experiencias de los hombres (Durand, 2008: 76), las que son expresados en su cotidianidad a través de sus idiomas, creencias y costumbres, a pesar de encontrarse en una situación similar a la proposición darwiniana que hacía referencia sobre la "supervivencia" solo de los más fuertes quienes logran adaptarse a los nuevos cambios que obliga esta nueva normalidad (Moreno, 2020:1).

Asimismo, el hombre desde su aparición sobre la faz de la tierra, siempre hizo frente a diversos obstáculos o desafios que estas las ofrecian, gracias a ello ha sufrido un proceso de evolución cognitiva como dijera (Tylor, 1889: 245), y los cambio como desarrollo en los diversos aspectos de la vida, como señala (Pariente, 2010: 3-7). Esto gracias a su racionalidad: inteligencia y voluntad.

Desde la vida social en comunidad y con presencia fisica, a la cual estábamos acostumbrados, hasta la primacía de la comunidad virtual o llamado también sociedad 2.0, ha revolucionado las relaciones sociales (Caldevilla, 2010: 45) y (Vásquez, 2010: 55-58). Pero cabe destacar que estos resultados se vienen logrando gracias a la creatividad, propuesta e innovación que muestran los hombres para superar cada obstáculo que se presenta cotidianamente.

Por otra parte, la cultura como un conjunto de valores materiales y espirituales fueron creados, aplicados y transmitidos por diversos procedimientos que estableció el hombre a través de su devenir histórico. Esto, determina ciertos estilos de comportamiento común y decisión en los individuos.

Nunca antes como ahora, una enfermedad se habia posesionado en nuestra cotidianidad donde, el pensar, sentir y actuar como considera (Harris, Bordoy, Revuelta \& Velasco, 1990: 4) y (Chanca, Ávila \& Aliaga, 
2020: 72) giran en torno a ella. A esto se suma el papel protagónico que vienen cumpliendo los diversos medios de comunicación que brindan información subalterna y contrapuesta que influyen directamente en las percepciones y perspectivas de la sociedad en general.

Muestran datos estadísticos ensimismados por una parte $y$ preocupante y traumatizantes por otra, a ello se suman casos que muchas veces superan la ficción, hechos que vienen afectando la salud mental de los individuos, quienes se sienten inestables y desconfiados frente a lo desconocido. Evidenciándose en la prensa escrita, la radio, la televisión y las diversas redes sociales que hoy conocemos sobre lo que viene generando la COVID-19 (Arango, Chanca \& Ñahuincopa, 2021: 18).

La crisis sanitaria que vivimos, no solo es resultado exclusivo de la aparición y propagación del Virus de Wuhan sino, además, responde a una serie de procesos de larga data que han sido dejados de lado por los gobiernos de turno.

Estas condiciones se han visto seriamente afectadas por las medidas de confinamiento y distanciamiento social ya que la población no cuenta con ingresos fijos ni seguro social.

Cada cual, a su modo, ha generado una serie de estrategias para poder generar ingresos que les permita subsistir y estos en su mayoría están ligados al comercio, al transporte $u$ otras actividades informales principalmente (Corona \& Morayta, 2021: 13).

Hoy en día prima la angustia y el miedo al contagio en la población, pero por encima de lo referido, se sobrepone la necesidad de saciar el hambre, (Trujillo, 2020: 90) el cual obliga a enfrentar cotidianamente esta realidad.

Sumado a ello, tenemos el incremento de la inseguridad ciudadana, la proliferación de la delincuencia, la presencia de actitudes xenofóbicas o 
racistas, entre otras. Un Estado inoperante, que solo dispone de "policias de balcón" como refiere (Cabrera, 2020: 211), que solo son meros espectadores, no se inmutan ante lo que viene ocurriendo en las calles, a causa de la pérdida de autoridad. Expresiones como estas: ya me cansé, que puedo hacer, hago lo que puedo, no hacen caso, entre otros, implica resignación y conformismo.

Ni la ciencia médica ni los diversos sistemas de salud, no estaban preparados para afrontar la pandemia de la COVID-19 y la población expuesta y desguarnecida en su totalidad. Esta desprevención ha ocasionado hasta el momento, la pérdida de más de 3 millones de vidas humanas y cerca de 150 millones de infectados, lo que para algunos analistas es la fragilidad que muestra el modelo neoliberal (Silva, 2020: $1)$.

También se conoce que las grandes empresas dedicadas a este rubro vienen produciendo un total de 11 vacunas en forma competitiva y que hoy se hallan en el mercado, tras haber pasado la tercera fase de prueba que exige la organización mundial de la salud (OMS). Y, más de 200 se hallan en proceso.

En el caso de las vacunas que están orientadas a controlar la COVID19 en el Perú, viene siendo cuestionadas por un gran sector poblacional, quienes manifiestan que existe corrupción en los procesos de negociación que se viene realizando para su adquisición por parte de las autoridades y funcionarios de alto nivel que son los responsables de este proceso.

Uno de los problemas que viene afrontando la sociedad en su conjunto, del cual forma parte el Estado peruano, es la difusión y confiabilidad de la información en los diversos medios de comunicación de señal abierta y espacios virtuales -redes sociales-, donde se vienen difundiendo 
diversas posturas sobre la seguridad y beneficios de las vacunas que permita controlar la pandemia y las nuevas cepas de la COVID-19.

Etapa que apertura una luz de esperanza y solución al problema que venimos enfrentando. Se sabe también que las vacunas tienen la particularidad de no solo proteger a los que lo reciben sino, además protegen a las personas que lo rodean (Zonenszain, 2021: 227). Se oyen opiniones a favor y en contra, muestran con claridad los intereses económicos, sociales y políticos de los diversos grupos de poder, quienes pugnan por imponer sus ideas.

A ello se suma el periodo de campaña electoral que vive el Perú para elegir al nuevo presidente de la República, aquí también vierten sus ideas diversas sobre el tema generando mayor incertidumbre y duda en la población.

Como parte del proceso de inmunización llegaron al Perú, en estos últimos dos meses, dos tipos de vacunas: la Sinopharm proveniente de China y la Pfizer de Estados Unidos.

La primera no logró las expectativas dentro de la población, supuestamente por su baja efectividad que muestra los resultados del estudio preliminar: $33.3 \%$ para la cepa de Wuhan y $11.5 \%$ para la cepa Beijín. Este dato fue difundido por el exjefe del Instituto Nacional de Salud (INS) Ernesto Bustamante. La segunda vacuna tendría el 79.34\% de efectividad que presentan a escala internacional.

Igualmente, la proliferación de noticias falsas, sesgadas o tergiversadas de dudosa procedencia, (Garcia, 2020: 1), viene tomando cuerpo en las redes sociales, las cuales tienen gran influencia en el imaginario colectivo y que puso ya en tapete serias dudas de la esperada efectividad causando incredibilidad generalizada. 
Estos sucesos conllevan a la toma de decisiones inadecuadas por la limitada información que tienen sobre el caso, notándose con claridad la poca presencia de la información oficial de las entidades responsables y las sociedades científicas existentes en el país. Estas entidades se hallan desacreditadas por los casos y acontecimientos que se ventilan en los medios de comunicación "vacunagate" (Alberto, 2021: 37).

Cabe también la reflexión sobre la relación social de cara a cara que mantendremos en esta etapa de la nueva normalidad. Como efecto cultural estará impregnada de angustias y temores a pesar de haber sido afectado y sabiendo que ya tendrá la oportunidad de ser vacunado.

Son aspectos muy dificiles de comprender porque son tramas culturales que perdurarán en cada individuo.

Imaginemos lo que pasará al volver a nuestros centros laborales, ¿será igual que antes? ¿Cómo será nuestro comportamiento? ¿Cambiarán las rutinas de socialización? Creo que las respuestas son poco esperanzadoras. Ya no volveremos a lo que fue antes de la pandemia.

Las prácticas de higiene, el distanciamiento social, el uso de las mascarillas, entre otros, son nuevos hábitos que llegaron con la pandemia y nos acompañarán al menos por un largo tiempo (Martínez, 2021: 5-9).

Algunos estarán de acuerdo con nuestros planteamientos en estas páginas, otros no, esto dependerá de los intereses individuales o colectivos que persigan, así como de la influencia de sus culturas y sociedades de donde provienen. 


\section{El enfoque ético filosófico: el homo homini lupus}

Como sabemos, la filosofia es un modo de saber de la realidad como las demás ciencias: la física, las matemáticas, la política, la biología, etcétera. El gran genio Aristóteles definió como la ciencia que estudia el ente por las últimas causas. No es fácil definir con palabras sencillas y precisión esta ciencia. ¿Cuál es el papel de la filosofia? El filósofo no ofrece respuestas inmediatas de los acontecimientos, sino ve la realidad donde otros no los ven o ven cosas normales o no les dice nada: lo ve como de una montaña, va oteando los problemas trascendentales con una visión global.

Tras los problemas trata de encontrar la verdad de las causas radicales, el porqué de esos problemas. Analiza las cosas para ayudar encontrar la verdad y la felicidad humana. En otras palabras, se preocupa e intenta responder -entre otras cuestiones- a estas interrogantes: ¿quiénes somos realmente? ¿qué hacemos en esta vida? ¿cuál es nuestro destino? Le preocupa también problemas fundamentales como la inmortalidad, pobreza, el bullyn, el amor, y la corrupción como sucedió con las vacunas "VIP" en las altas esferas del gobierno peruano.

Por otro lado, Pilar Mazzeti, cuando asumió la función del Ministerio de Salud, dijo que no estuvo para filosofar, sino para actuar ya, como si el acto de filosofar fuera perder el tiempo. Ya sabemos cómo acabó la gestión de esta señora. Cuán importante es reflexionar, principalmente si nuestros actos son correctos éticamente: ya sea a nivel individual, familiar y con más razón como parte del gobierno. Es fundamental, en esta coyuntura actual, analizar las cosas para actuar con criterio y "no actuar por actuar". 
El filósofo Tomás Hobbes en su obra el leviatán aborda el homo homini lupus, esto es, el hombre es lobo para el hombre. Este pensador destaca realmente lo que muchas veces somos los humanos: soberbios, arrogantes y egoístas, que pensamos en uno mismo sin importarnos el prójimo.

Tomás de Aquino siglos antes ya había afirmado que la raíz de todos los pecados o errores graves era la soberbia. Esta actitud egoísta e inhumana hemos palpado en carne propia o ajena en los inicios de la pandemia, en el confinamiento social obligatorio, la compra de las mascarillas, los medicamentos y la actitud de las clínicas. También en la adquisición y administración de las vacunas.

Nada más enterarnos de la cuarentena e incluso antes, cómo algunas personas se acercaban a los supermercados y tiendas comprando desesperada y egoístamente: el papel higiénico, alcohol, lejía y algunos productos de primera necesidad. Este dato empírico en terminología kantiana fue respaldo en el mundo entero tanto por las noticias televisivas, radiales como en redes sociales.

Si uno tiene mucho dinero puedo comprar todo lo que pueda, y no dejar nada para los demás. No interesa en absoluto la situación de los demás. ¿Por qué no puedo comprar lo necesario? Este tipo de actitudes no mostraron otra cosa que la primacía de la ley del más fuerte, y nos ha hecho recordar a Darwin, la lucha por la supervivencia o la selección natural, donde sobrevive el más fuerte.

Lo mismo sucedió con la compra de las mascarillas, -que para no contagiarse ni contagiar a los demás del virus de Wuhan se convirtió en hábito obligatorio- ante tanta demanda subió también de precio. Ahora bien, ¿qué trae en el fondo, el uso de las mascarillas desde el punto de vista filosófico? 
La otra cara de la moneda de este prosopon -aparte que los delincuentes pueden usar para cometer sus fechorias sin ser reconocidos, pues, la cara lo tienen cubierta- Por otra parte, quizá por querernos proteger más con esta prenda, terminemos viendo al prójimo como un enemigo. ¿Esto no está fomentando el predominio del individualismo? Como el coronavirus se contagia de persona a persona, con este material evitamos el contagio. A veces, da la impresión cuando uno sale a la calle: que todo el mundo está contagiado y tratamos de evitar en la medida de lo posible los contactos con nuestros semejantes. Este modus vivendi está transformándose en un hábito de vida, ¿no quedará grabado en el subconsciente usando la terminología del fundador del psicoanálisis Freud? Y ¿cómo podrá afectar en nuestro comportamiento en el futuro? El uso de las mascarillas es una necesidad primordial por ahora hasta estar vacunados.

Un día desecharemos y se quedará como algo anecdótico. Pero, ¿tendrá alguna repercusión en nuestra psique o conciencia? Puesto que esta crisis sanitaria hizo estragos también la salud mental ocasionando niveles altos de estrés, ansiedad y depresión. Y cuando pase la pandemia se verá con más claridad las secuelas que dejó a los que se han infectado en la forma de pensar y actuar, no solo en lo fisiológico.

Por otra parte, es digno de consideración el precio de los medicamentos y la actitud de las clínicas ante esta situación. En el Perú, estas instituciones hicieron y están haciendo lamentablemente sus bisnes a costa de esta crisis. Sus cobros exorbitantes e inhumanos llevados por la ambición, van fomentando una actitud capitalista sin parámetros éticos, es decir, yo me hago rico sin que me importe los demás: "el fin justifica los medios".

Internarse en una clínica particular llegó incluso a costar casi medio millón de soles, por ello algunas personas han perdido sus viviendas, 
vehículos, etc., por conseguir el dinero para cubrir sus deudas en dichas instituciones. Lo mismo pasó con el costo de algunas pastillas o medicamentos para paliar los malestares del coronavirus. Por ejemplo, el paracetamol se quintuplicó su valor. Ni hablar del oxígeno, que se elevó el importe por las nubes. Quisiéramos destacar al Ángel del oxígeno ${ }^{5}$, quien a pesar que los demás manejaban un monopolio comercial, ofreció otra alternativa con precio justo. Lamentablemente esta persona falleció, pero nos dio un gran ejemplo de justicia, humanismo, solidaridad y honestidad.

Ahora bien, ¿qué ocurrió con la compra, manejo y aplicación de las vacunas? "Cerca de 2 dos millones de infectados y casi 60.000 muertos, Perú es uno de los países de América Latina más afectados por la pandemia" (OMS, Wikipedia \& Baidu, 2021). Sin embargo, en la compra y administración de las vacunas, salió también a relucir la ley del más fuerte, el poder político y económico.

Mientras muchos estuvimos sumidos en el dolor y sufrimiento social batallando por salvar la vida de nuestros seres queridos: madrugando y haciendo inmensas filas de espera para conseguir el oxígeno, las colas de eterna duración en los hospitales para saber la situación de un familiar o amigo y esperando la ansiada vacuna.

La actitud indignante del expresidente y los funcionarios públicos, que juramentaron cumplir fielmente sus deberes. Elegidos para servir al país, pero optaron por servirse de él para sus intereses. "Vizcarra habia recibido dos dosis de la vacuna contra la COVID-19 de la empresa china Sinopharm en octubre, cuando aún estaba al frente del gobierno y se estaba llevando a cabo el estudio clínico de la misma en el país. (...) la lista

\footnotetext{
5 Mario Romero Pérez, es uno de los empresarios que vendía el oxígeno medicinal a precio justo, falleció 19/07/2020 a causa de la COVID-19. Más conocido como el "Ángel del oxígeno de San Juan de Miraflores".
} 
de los 487 inoculados, donde aparece como "invitado" Vizcarra $y$, registrados como "entorno cercano", figuran los nombres de su esposa y su hermano" (Ibidem).

Aparentemente, el exmandatario "Recluyó a millones de ciudadanos y les hizo sentir que era el gran padre que estaba protegiendo a todos" (Jara, 2021). En el fondo, fue una cachetada a todos los valores: veracidad, honestidad, solidaridad, empatía y compasión. Fue una traición a cada peruano y peruana, especialmente a la gente humilde. O sea, los que están en el poder, pueden hacer todo e incluso saltando los principios morales, la ética profesional, aunque según Humberto Jara algunos políticos son psicópatas por eso miente con muchísima frecuencia. Ahora bien, ¿la ambición o el afán de dinero puede convertir a una persona en un psicópata o viceversa?

El escándalo de las vacunas incluso saltó a las esferas internacionales. Pero el problema de los problemas es la corrupción y cómo encontrar el remedio, si algún día podríamos conseguirlo. Fue una exasperación para miles de peruanos, pues los "funcionarios del Gobierno y sus círculos intimos, incluidos familiares, supuestamente se aprovecharon de sus puestos para acceder a una vacuna a la que no tenian derecho" (Romo, 2021). Esto fue una decepción total en esta coyuntura. Como dice José Ugaz, un abogado de Derechos Humanos del Perú y expresidente de Transparencia Internacional: ... muchos peruanos están acostumbrados a "decepción tras decepción" de sus lideres elegidos a estas alturas. (...) Hemos visto gobiernos profundamente arraigados en la corrupción, con débiles capacidades de gobierno, mintiendo permanente $y$ sistemáticamente al pueblo, y anteponiendo los intereses de ellos mismos y los de sus partidos y círculos internos al pais; lo que también ha sucedido durante la pandemia. (Ibidem). 
Ha primado el egoísmo que la solidaridad en nuestro comportamiento: en los que fueron a las tiendas arrasando con todo al principio de la pandemia sin pensar en el resto, en el negocio de las mascarillas, medicinas, el oxígeno y en la compra y administración de las vacunas: ese monstruo, el leviatan, que nos convierte el lobo para nuestro semejante.

Para explicar el engranaje de la corrupción, hace falta enfocar que la política en los últimos tiempos se ha deslindado de la ética, e incluso muchas veces es maquiavélica, porque "el fin justifica los medios": hacer cualquier cosa con tal que se mantenga en el puesto y llegar como sea, aunque usando medios ilícitos al poder: difamando, pagando e incluso matando algún opositor.

La filosofia no puede comulgar con la corrupción, porque está precisamente para preservar, sacarla invitándonos a la reflexión, al pensamiento crítico, y condenar los comportamientos ilícitos para no ser cómplices. Porque la solidaridad, honestidad y veracidad solo son grandes ideales, inalcanzables para los corruptos, egoístas o psicópatas.

Finalmente, es relevante preocuparnos por la crisis económica, pero mucho más alarmante es la crisis de los valores humanos, por ejemplo, la falta de honestidad, que es la causa de aquella. Podríamos preguntarnos, ¿qué es lo que está pasando, no deberíamos ser en este tiempo tan dificil al menos un poquito solidarios?

\section{Conclusión}

La pandemia de la COVID-19 en el Perú nos hecho experimentar la dimensión social del dolor tanto personal, familiar e institucional. Pues, cuando uno se contagia o fallece alguien sufre. Y muchos hemos perdido amistades, compañeros de trabajo o algún miembro de la familia. 
La llegada de las vacunas al Perú, abre una etapa de incertidumbre en la población, muchas familias ven con optimismo y esperanza para solucionar el problema generado por el coronavirus, que les conllevó a convivir con el dolor y sufrimiento, mientras que otros son incrédulos por los actos ilícitos y diversas informaciones que vienen circulando en las redes sociales, esto se debe a las diversas culturas que perviven con sus propias costumbres, creencias y experiencias. Sin embargo, la actitud desleal de la clase politica con respecto a las vacunas es, inadmisible y acto de desfachatez. El aprovechamiento y la sagacidad para beneficiarse de la inmunización marcan la desconfianza en la población que sigue esperando que sea equitativa.

En el Perú, tanto en el pasado como en el presente, -con tantos presidentes corruptos y su entorno, no solo ahora- estamos padeciendo evidentemente una crisis de valores y de humanidades. Este brete nos hace más miserables que la misma miseria económica. La corrupción es una pandemia sin curación hasta el momento. Necesitamos detenernos al menos un momento y reflexionar. Para ello, hace falta la humildad sincera, reconocer los errores y cambiar. El cambio tiene que venir necesariamente de uno mismo y nadie más. Mientras que no cambiemos personalmente cada uno de nosotros no podremos cambiar la sociedad. Porque si cambiamos, podriamos cambiar nuestra familia, si cambia nuestra familia, mejorar nuestro pueblo. Esto es una cadena hasta llegar hasta la esfera del Estado. La peor pobreza es la miseria de valores o virtudes humanas. Asimismo, en la práctica, los países ricos o emergentes son los primeros en comprar y usar la vacuna. ¡Sólo hay una cosa verdadera, con la vacuna muchas empresas se hacen y harán cada vez más ricas! Incluso muchas veces violando los parámetros éticos.

Finalmente, es interesante considerar éticamente, que en todos los gobernantes peruanos -con pandemia y sin ella- existe un denominador 
común: la corrupción. Por eso, es fundamental antes de elegir autoridades de ámbito nacional, regional o local, conocer su formación ético profesional y analizar los mínimos señales de honestidad y transparencia para ocupar los cargos públicos o privados. 


\section{Referencias}

Alberto, M. Á. (2021). El 'vacunagate' peruano salpica al nuncio. Vida Nueva, (3213), 37.

Álvarez, R. A. (21 febrero 2021). Ayudaría que Málaga diga quién dijo no: "Para levantar el devastado espíritu nacional de este país". https://larepublica.pe/opinion/2021/02/21/ayudaria-quemalaga-diga-quien-dijo-no-por-augusto-alvarez-rodrich/

Arango Olarte, R., Chanca Flores, A., \& Ñahuincopa Arango, A. (2021). Reflexiones sobre la otra cara de la pandemia en los Andes del Perú. Revista Científica Arbitrada de la Fundación MenteClara, Vol.6 (217). doi: https://doi.org/10.32351/rca.v6.217

Cabrera, E. A. (2020). Actividad fisica y efectos psicológicos del confinamiento por covid-19. Revista INFAD de Psicología. International Journal of Developmental and Educational Psychology. 2(1), 209-220.

Caldevilla, D. D. (2010). Las Redes Sociales. Tipología, uso y consumo de las redes 2.0 en la sociedad digital actual. Documentación de las Ciencias de la Información, 33, 45-68.

Campos, M. A. (13 de febrero de 2021). "La cantidad de mentiras que se apilaron, una tras otra, en las declaraciones de Vizcarra es impresionante". https://elcomercio.pe/opinion/columnistas/martin-vizcarra-la-vacuna-y-la-mentira-pormaria-alejandra-campos-sinopharm-noticia/

Campos, M. A. (20 febrero 2021). El riesgo es confiar: "la revelación de la vacunación de Pilar Mazzetti y Martín Vizcarra fue celebrada por sus opositores como un gol de media cancha en el último minuto del partido". https://elcomercio.pe/opinion/columnistas/vacuna-contra-elcoronavirus-martin-vizcarra-el-riesgo-es-confiar-por-maria-alejandra-campos-sinopharmnoticia/

Chanca, A., Ávila, J. \& Aliaga, C. M. (2020). Percepción cultural de los pobladores sobre el Programa Social Juntos en el Valle del Mantaro. Socialium, 4(1), 68-83. https://doi.org/10.26490/uncp.s1.2020.4.1.510

Corona-De la Peña, L. E., \& Morayta, M, L. M. (2021) Miradas históricas y antropológicas sobre la pandemia, COVID-19.

De Arruda, C. N., Marqués, M. H. \& Álvaro, J. L. (2020). Relaciones entre valores humanos y sindrome de burnout: una revisión sistemática. Revista de la Asociación Española de Especialistas en Medicina del Trabajo, 29(4), 357-373.

Del Río, P. (21 de febrero de 2021). La muerte les sienta bien: "si bien todas las caras de la desigualdad, la corrupción y el abuso de poder son deplorables; esta ha resultado devastadora". https://elcomercio.pe/opinion/columnistas/la-muerte-les-sienta-bien-porpatricia-del-rio-covid-19-vacunagate-martin-vizcarra-noticia/

Di Franco, M. G. (2020). Tiempos de pandemia, tiempos de posibilidades. Praxis Educativa, 24(2), 1 3.

D'Souza, M. F. (2020). Responsabilidade social corporativa modera a relação entre o traço maquiavélico e o gerenciamento de resultados? Revista de Educação e Pesquisa em Contabilidade (REPeC), 14(4).

Durand, L. (2008). De las percepciones a las perspectivas ambientales: una reflexión teórica sobre la antropología y la temática ambiental. Nueva antropología, 21(68), 75-87.

García, M. D. (2020). "Infodemia global. Desórdenes informativos, narrativas fake y fact-checking en la crisis de la Covid-19". Profesional de la información, v. 29, n. 4, e290411.

https://doi.org/10.3145/epi.2020.jul.11 
Gastelumendi, R. (19 febrero 2021). El lado amable del Vacunagate 19: "Nada más honesto y sincero que el egoísmo y los actos encubiertos". https://larepublica.pe/opinion/2021/02/19/el-ladoamable-del-vacunagate-por-rene-gastelumendi/

Giroux, H. \& Proas, L. (2020). La pandemia de Covid-19 está exponiendo la plaga del Neoliberalismo. Praxis educativa, 24(2), 1-13.

Harris, M., Bordoy, V., Revuelta, F. \& Velasco, H. M. (1990). Antropología cultural. Madrid: Alianza editorial.

Herskovits, M. J. (1952). El hombre y sus obras: la ciencia de la antropología cultural (No. GN490 H4e). México: Fondo de cultura Económica.

Jara, H. (14 Feb 2021). Vizcarra y la mentira patológica. https://www.expreso.com.pe/politica/vizcarra-y-la-mentira-patologica/

Jesús, T. A., Sarmento, M. \& Duarte, M. (2018). Ética e responsabilidade social. Dos Algarves: A Multidisciplinary e-Journal, (29), 3-30.

Martínez, A. N. (2021). Las redes académicas y la interconectividad: frente a la nueva normalidad. Estudios sobre las culturas contemporáneas, (52), 5-9.

Martinez, E. (1975). Diccionario Santillana 2. Gráficos Mateo Cromo S. A., Madrid España

Mendoza, R. (21 de febrero 2021). César R. Nureña: "De un modo u otro, todos están metidos en algún tipo de argolla": https:/ /larepublica.pe/domingo/2021/02/21/cesar-r-nurena-de-unmodo-u-otro-todos-estan-metidos-en-algun-tipo-de-argolla/

Montero, P. (24 febrero 2021). "Hay una sola palabra que describe mis sentimientos: ROTA, y no soy la única...". https://larepublica.pe/sociedad/2021/02/24/rotos-por-patricia-montero/

Moreno, P. M. (2020). "Nueva normalidad": ¿hacía otra manera de vivir? Temperamentvm, 16, e20161-e20161.

Noreña, D. L. (2020). Desafios para la salud colectiva en el cuidado con personas, familias y comunidades, vulnerables socialmente, frente a la pandemia. Aquichan, 20(4), 1-1. DOI: https://doi.org/10.5294/aqui.2020.20.4.1

OMS, Wikipedia y Baidu (22 de abril 2021). https://hgis.uw.edu/virus/

Ortiz, B. P. (19 de febrero de 2021). Cínicos, farsantes y cobardes Ex viceministro de Salud Luis Suárez Ognio se vacunó y facilitó lo propio para sus familiares.

https://elcomercio.pe/lima/sucesos/cinicos-farsantes-y-cobardes-por-pedro-ortiz-bisso$\underline{\text { noticia/ }}$

Pariente F. J. (2010). Proceso de cambio y desarrollo en las organizaciones. Recuperado de http://academia.uat.edu.mx/pariente/Libros/Pariente_Procesos\%20de\%20cambio\%20y\%20 DO.pdf

Romo, R. (18 febrero, 2021). Vacunagate: el furor de las vacunas contra el coronavirus pone de relieve una larga historia de conducta indebida de funcionarios electos en Perú. https://cnnespanol.cnn.com/2021/02/18/vacunagate-el-furor-de-las-vacunas-contra-elcoronavirus-pone-de-relieve-una-larga-historia-de-mala-conducta-de-los-funcionarioselectos-en-peru/

Silva, A. L. (2020). Cuba y las enseñanzas que dejan seis meses de enfrentamiento a la Covid 19.

Tala, Á. \& Valenzuela, J. (2020). Si Quiero Sanar, Debería Perdonar: Una Revisión Sobre el Perdón y la Salud. Revista chilena de neuro-psiquiatría, 58(3), 251-258.

Trujillo, P. (2020). Si salimos nos mata el virus, si nos quedamos nos mata el hambre. Cadernos De Campo (São Paulo 1991), 29(supl), 85-93. 
Tylor, E. B. (1889). Readings in Cross-Cultural Methodology. Journal of the Royal Anthropological Institute of Great Britain and Ireland, 18, 245-272.

Vásquez, A. A. (2010). Ciberantropología: Desentramando la sociedad 2.0 desde la región del software libre. Revista de estudios extremeños, 66(1), 51-72.

Zonenszain, L. Y. (2021). Las vacunas contra el Covid-19: dos dilemas éticos a considerar. Revista de Medicina y Ética, 32(1), 215-231 